\title{
A Case of Kwashiorkor Presenting with Pericardial Effusion
}

\section{Taheri S*, Surak A, Bravo G, McMurray A and Altamirano-Diaz L}

Department of Paediatrics, Children's Hospital, London Health Sciences Centre, Western University, London, UK

\begin{abstract}
Introduction: Kwashiorkor is a type of protein-calorie malnutrition often seen in children of impoverished countries and famine. It is a result of insufficient protein intake in the context of adequate caloric intake.

Case report: We report a case of a 13-year-old male with trisomy 21 in Southwestern Ontario, Canada who presented with bilateral pneumonia, pericardial effusion and peripheral edema. Evaluation revealed severe dietary restriction, consistent with kwashiorkor. Child was placed on severely restrictive diet, particularly limiting dairy intake to one daily cup of plain, unfortified yogurt. His hospital course was complicated with severe hypocalcemia, hypomagnesemia and hypophosphatemia. These findings resolved gradually upon slow introduction of well-balanced diet and adequate caloric and protein intake.
\end{abstract}

Conclusion: Malnutrition is often underdiagnosed or misdiagnosed in developed countries with devastating outcomes if unrecognized. This makes it imperative to consider this diagnosis, recognize potential risk factors and be prepared to accurately assess overall nutritional status.

Keywords: Malnutrition; Kwashiorkor; Case report; pneumonia; Respiratory; Pericardial effusion

\section{Background}

Kwashiorkor is a type of protein-calorie malnutrition, most often seen in children of impoverished countries or areas of famine. Kwashiorkor, first described by Cicely Williams in 1935, is thought to be secondary to inadequate dietary protein intake in the presence of sufficient caloric intake [1,2]. Children placed on restrictive diets by "well-intentioned" parents, as a result of concern for food allergies, have been reported to be at risk of nutritional deficiencies, such as kwashiorkor [3]. Associated physical findings may include dermatitis, protuberant abdomen, thinning hair, and "bull-dog" face. Clinical findings may also include weight loss/ failure to thrive, delayed linear growth, irritability, and lethargy. We describe a complicated case presenting with pericardial effusion and pneumonia, in which the diagnosis was reached by supporting history, examination and laboratory findings.

\section{Case Report}

A 13-year-old male with trisomy 21 and complex past medical history, was transferred from a peripheral hospital for lethargy, pneumonia, and worsening respiratory distress. Due to worsening respiratory status, he was admitted to the regional pediatric intensive care unit, where a large pericardial effusion was later confirmed on echocardiography. Dietary history revealed a prolonged, inadvertent administration of a restricted diet, deficient in protein and several other nutrients. The patient's parents believed their child had a milk allergy and consequently restricted his daily intake. Upon further investigation, it was revealed that his functional status had greatly deconditioned over the course of 3 months, from being previously able to ambulate with a walker, to now no longer making any transfers and being bedridden. The past medical history was significant for trisomy 21 syndrome, seizure disorder, global developmental delay, small atrial septal defect (ASD), obstructive sleep apnea, gastroesophageal reflux disease, and hypothyroidism. His medication regimen on admission included valproic acid, thyroxine, lansoprazole and domperidone. There was a reported allergy to lamotrigine (Stephens-Johnson Syndrome in the past). His immunizations were up-to-date. The family and social histories were unremarkable. The patient was born in Canada. He is the first child born to parents of East Indian descent (unknown exact geographic region).

Beside the trisomy 21 features, the physical examination revealed a pale, lethargic boy with facial edema, hepatomegaly, ascites, pedal edema, and non-specific dermatitis. His weight on admission was well below the $5^{\text {th }}$ percentile on both the traditional CDC Growth Charts for Children with Down syndrome, as well as the newer growth charts based on the Down Syndrome Growing Up Study (DSGS) [4]. His midupper-arm circumference was $<11.5 \mathrm{~cm}$; weight-for-height $Z$ score $<3$. Initial echocardiography showed a significant pericardial effusion with echocardiographic evidence of tamponade and mildly increased right ventricle systolic pressure, as well as a known small ASD (Figure 1). This was managed with high-dose ibuprofen for 10 days and 7-day course of prednisone, with no significant improvement in the effusion. Because of the lack of response to the anti-inflammatory drugs, other rare causes of pericardial effusion were considered; taking into consideration the history of poor weight gain, dietary restrictions and electrolyte abnormality, the diagnosis of Kwashiorkor was considered as a potential cause for the pericardial effusion. Upon admission, a Registered Dietitian was consulted to assess the adequacy of calcium intake given his critically low blood level. The Registered Dietitian conducted a 24 Hour Dietary Recall with the patient's mother and used the aid of measuring cups to help estimate usual volume. Mom reported that the diet consisted of pureed or well-mashed foods of cream of wheat, white rice, small amounts of lentils, spinach, carrots, unfortified (homemade) yogurt and ghee. Mom reported the patient does not consume any fruits or any other vegetables and has not consumed any liquid milk in many years. When comparing his best usual intake to Canada's food guide to healthy eating, on average, his

*Corresponding author: Taheri S, Department of Pediatrics, University of Western Ontario, London, UK, Tel: + 519-685-8500; E-mail: sepideh.taheri@Ihsc.on.ca

Received May 18, 2017; Accepted May 25, 2017; Published June 09, 2017

Citation: Taheri S, Surak A, Bravo G, McMurray A, Altamirano-Diaz L (2017) A Case of Kwashiorkor Presenting with Pericardial Effusion. Med Rep Case Stud 2: 134. doi: $10.4172 / 2572-5130.1000134$

Copyright: (C) 2017 Taheri S, et al. This is an open-access article distributed under the terms of the Creative Commons Attribution License, which permits unrestricted use, distribution, and reproduction in any medium, provided the original author and source are credited. 


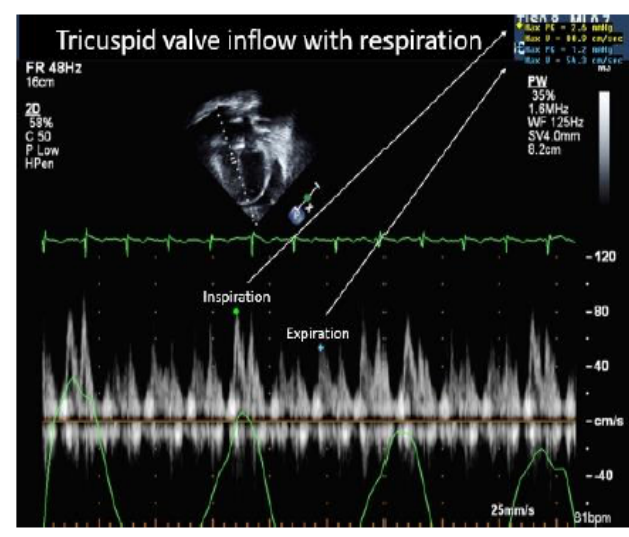

Figure 1: Pericardial tamponade in a Patient with Kwashiorkor: Tricuspid valve inflow during respiration with evidence of pericardial tamponade on admission.

\begin{tabular}{|l|l|l|l|}
\hline Food Group & $\begin{array}{l}\text { Servings } \\
\text { Consumed }\end{array}$ & $\begin{array}{l}\text { Recommended } \\
\text { servings for Age }\end{array}$ & Comments \\
\hline Grain Products & 2.6 & 6 & $\begin{array}{l}\text { White rice, Cream of } \\
\text { wheat }\end{array}$ \\
\hline Vegetables and Fruit & 4 & 6 & $\begin{array}{l}\text { Vegetables only } \\
\text { spinach and carrot) } \\
\text { no fruit }\end{array}$ \\
\hline Milk and Alternatives & 1.3 & $3-4$ & Homemade yoghurt \\
\hline Milk and Alternatives & 1.3 & $1-2$ & Yellow lentils \\
\hline
\end{tabular}

Table 1: Number of servings of the various food groups and how it compares to the Canadian food guide.

\begin{tabular}{|l|c|c|}
\hline Macro nutrient & \% of calories consumed & DRI Recommendation \\
\hline Carbohydrate & $45 \%$ & $46-65 \%$ \\
\hline Protein & $11 \%$ & $10-30 \%$ \\
\hline Fat & $44 \%$ (26\% saturated fat) & $25-35 \%$ \\
\hline
\end{tabular}

Table 2: Macronutrient distribution.

\begin{tabular}{|l|c|c|}
\hline Micronutrient & Amount Consumed & DRI for age \\
\hline B12 & $0.9 \mathrm{mcg}$ & $1.8 \mathrm{mcg}$ \\
\hline B2 & $0.78 \mathrm{mg}$ & $0.9 \mathrm{mg}$ \\
\hline Niacin & $7 \mathrm{mg}$ & $12 \mathrm{mg}$ \\
\hline Vitamin D & $2.25 \mathrm{mcg}$ & $15 \mathrm{mcg}$ \\
\hline Vitamin E & $4.6 \mathrm{mg}$ & $11 \mathrm{mg}$ \\
\hline Calcium & $513 \mathrm{mg}$ & $1300 \mathrm{mg}$ \\
\hline Selenium & $27 \mathrm{mcg}$ & $40 \mathrm{mcg}$ \\
\hline Zinc & $4 \mathrm{mg}$ & $8 \mathrm{mg}$ \\
\hline Omega 3 & 0.11 & $1.2 \mathrm{~g}$ \\
\hline Omega 6 & 0.57 & $12 \mathrm{~g}$ \\
\hline Panthothenic Acid & $2.61 \mathrm{mg}$ & $4 \mathrm{mg}$ \\
\hline Phosphorus & $782 \mathrm{mg}$ & $1250 \mathrm{mg}$ \\
\hline
\end{tabular}

Table 3: Dietary reference intake (DRI) comparison.

intake is below the recommendations for ages for the majority of food groups (Table 1). The 24-hour Dietary Recall was than analyzed using ESHA, a computer diet analysis program to help assess the intake of micro and macronutrients. When comparison to the recommendations for age, the patient's intake was well below recommendations for a variety of macro and micronutrients (Tables 2 and 3). He was found to have multiple severe nutritional deficiencies, including protein, calcium, magnesium, 25-Vitamin D, phosphate, and iron (Table 4). He was asymptomatic despite the very low ionized calcium levels. He required supplementation with intravenous calcium gluconate as well as calcium carbonate via NG tube for his long-term supplementation.
The patient, on his best intake consumed $1.47 \mathrm{~g} / \mathrm{kg}$ of protein (but more recently consuming $50 \%$ of this or $0.74 \mathrm{~g} / \mathrm{kg}$ ) which compares to $0.95 \mathrm{~g} /$ $\mathrm{kg}$ recommended for age. Once the patient became stable medically, the Registered Dietitian met with mom and dad on a number of occasions to provide nutrition education and a Pureed Diet Plan for home. This plan included 1800-1900 calories per day and provided recommended number of servings, serving sizes and additional recommendations for the parents to follow to help ensure that the patient had a well-balanced variety of macro and micronutrients. A written copy of the plan was given to parents for their use at home (Table 5). We also placed a referral for a Community Care Access Centre (CCAC) Registered Dietitian to continue to follow the patient and provide additional education and follow-up post hospital discharge. While in hospital, the patient also developed hyponatremia secondary to syndrome of inappropriate antidiuretic hormone (SIADH), which required acute treatment in the form of hypertonic saline and later fluid restriction. It was thought that his chronic illness and the pericardial effusion could be contributing to his SIADH. This patient's history, clinical picture, various electrolyte disturbances, and complications were consistent with Kwashiorkor malnutrition. With appropriate nutritional and caloric requirements, he became increasingly active. His ascites and hepatomegaly also resolved. The pericardial effusion, which had been initially treated with ibuprofen and prednisone to no effect, also improved with appropriate targeted nutritional therapy (Figure 2). After more than a month-long

\begin{tabular}{|l|c|c|c|}
\hline Blood work & Admission & Discharge & Normal Range \\
\hline lonized Ca (mmol/L) & 0.49 & 1.11 & $1.09-1.30$ \\
\hline $\mathrm{Mg}(\mathrm{mmol} / \mathrm{L})$ & 0.50 & 0.96 & $0.65-1.05$ \\
\hline $\mathrm{Na} \mathrm{(mmol/L)}$ & 123 & 133 & $135-145$ \\
\hline $\mathrm{Hb}(\mathrm{g} / \mathrm{L})$ & 66 & 96 & $125-160$ \\
\hline $25 \mathrm{Vit} \mathrm{D}(\mathrm{nmol} / \mathrm{L})$ & $<10$ & 31 & $75-250$ \\
\hline Albumin $(\mathrm{g} / \mathrm{L})$ & 28 & 30 & $38-54$ \\
\hline Phosphate $(\mathrm{mmol} / \mathrm{L})$ & 0.85 & 2.41 & $1.1-1.9$ \\
\hline Ferritin Ug/L & 39.9 & 26.5 & $30-400$ \\
\hline Iron $(\mu \mathrm{mol} / \mathrm{L})$ & 6 & $\begin{array}{c}\text { (was checked 3 } \\
\text { months following } \\
\text { discharge) }\end{array}$ & $8-29$ \\
\hline
\end{tabular}

Table 4: Nutritional and Electrolyte Deficiencies in a Patient with Kwashiorkor Malnutrition: These values are the actual laboratory results of this patient's blood work. All admission values are within two days of the patient's initial admission to hospital, with the exception of his sodium, phosphate and hemoglobin values, which denote the nadir of his anemia, hypophosphatemia and hyponatremia rather than his admission blood work. The discharge results are the most recent values prior to discharge and may not have been drawn on the exact discharge date. The findings show a significant improvement in all categories following refeeding, nutritional supplementation, and medication administration.
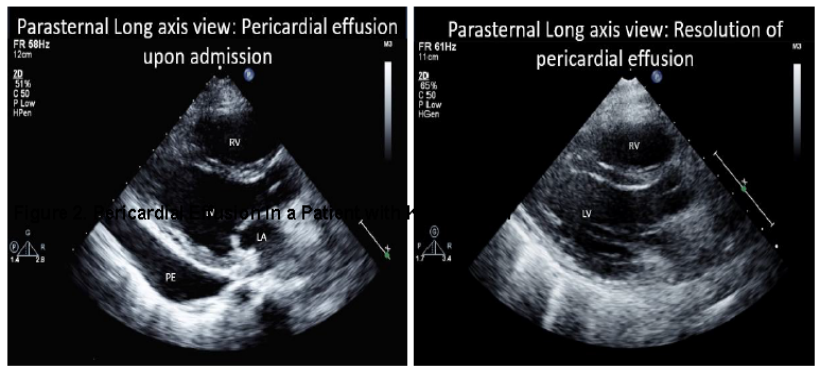

Figure 2: Pericardial Effusion in a Patient with Kwashiorkor: Pericardial effusion on admission (LEFT) with subsequent resolution (RIGHT) following appropriate therapy. The effusion was initially treated with a course of ibuprofen and prednisone, with minimal improvement. It was not until the Kwashiorkor diagnosis and ensuing management targeted at malnutrition that the effusion resolved. 


\begin{tabular}{|c|c|c|c|}
\hline \multicolumn{2}{|c|}{$\begin{array}{l}\text { Recommended Number of Food } \\
\text { Guide Servings per Day }\end{array}$} & What's a serving? & Recommendations \\
\hline Vegetables and Fruit & $5-6$ & $\begin{array}{l}\text { - } 1 \text { fruit or } 1 / 2 \text { cup fresh/frozen/canned fruit } \\
\text { - } \quad 1 / 2 \text { avacado } \\
\text { - } 1 / 2 \text { Cup fresh/ frozen/canned vegetables } \\
\text { - } 1 \text { cup raw leafy vegetables } \\
\text { - } \quad 1 / 2 \text { cup } 100 \% \text { juice }\end{array}$ & $\begin{array}{l}\text { Aim for } 1 \text { dark green (broccoli, spinach etc.) and } 1 \\
\text { orange vegetable (carrots, sweet potato, squash } \\
\text { etc.) per day } \\
\text { Use a variety of each every day } \\
\text { Raw Leafy Vegetables are low in calories so a } \\
\text { variety of non-leafy vegetables need to make up the } \\
\text { majority of servings per day }\end{array}$ \\
\hline Grain Products & $5-6$ & $\begin{array}{l}\text { - } 1 \text { slice bread } \\
\text { - } \quad 1 / 2 \text { bagel, pita, tortilla } \\
\text { - } \quad 1 / 2 \text { cup cooked rice, quinoa, couscous, pasta } \\
\text { - } \quad 1 / 2 \text { cup hot cereal/oatmeal/cream of wheat } \\
\quad 30 \mathrm{~g}(1 / 2 \text { to } 1 \text { cup }) \text { cold cereal }\end{array}$ & $\begin{array}{l}\text { Make half the grain products whole grain } \\
\quad \text { Use a variety of grain products every day }\end{array}$ \\
\hline Milk and Alternatives & $3-4$ & $\begin{array}{l}1 \text { cup of milk, fortified milk alternative (soy, almond, } \\
\text { etc.) or commercial supplement (i.e. Pediasure, } \\
\text { Ensure or Boost) } \\
\text {. } \quad 50 \mathrm{~g}\left(1 \frac{1}{2} \mathrm{OZ}\right) \text { Cheese } \\
\end{array}$ & $\begin{array}{l}\text { Use milk or fortified milk alternatives } \\
\text { Minimum } 2 \text { of the choice milk/milk alternative/ } \\
\text { commercial supplement }\end{array}$ \\
\hline Meat and Alternatives & $2-3$ & $\begin{array}{l}\text {. } \quad \text { Cup cooked legumes (benas, lentils) tofu } \\
1 / 2 \text { cup cooked fish, meat, poultry } \\
\text { - } \quad 2 \text { eggs (cooked) } \\
\text { - } \quad 2 \text { Tbsp peanut or nut butter }\end{array}$ & $\begin{array}{l}\text { Choose a variety of meat and/ or meat alternatives } \\
\text { (beans, lentils, tofu) and eat at least } 2 \text { servings of } \\
\text { fish each week }\end{array}$ \\
\hline Fats & 2-3 tablespoons & Use canola, Olive oils, soft margarines, butter & $\begin{array}{l}\text { Walnut oil is an excellent source of omega } 3 \text { and } \\
\text { omega } 6 \text { (include } 2 \text { tbsp per day) }\end{array}$ \\
\hline
\end{tabular}

Table 5: Pureed diet plan 1800-1900 calories per day.

hospital stay, all biochemical parameters had returned to normal, the patient had resumed oral feeding, and he was discharged in a stable condition on his home medications as well as several nutritional supplements.

\section{Limitations}

It is important to note that dietary analysis is limited to a single 24 hour recall provided by the patient's mother and that the recall estimated the patient's "best" intake. Also, the fact that the diet was initiated few years ago made it tricky to memorize it all in details.

\section{Discussion}

Kwashiorkor is a rare cause of pericardial effusion, and can be severe like in this case causing echocardiographic evidence of tamponed. There are many cases of Kwashiorkor malnutrition in U.S. literature that have described infants who have suffered significant dietary restriction by "well intentioned", but ultimately misguided, parents, as was the case in our patient. This child had previously been treated for inflammatory causes of pericardial effusion with no response. Additionally, his primary healthcare provider had never addressed his poor weight gain and nutritional status. The diagnosis of Kwashiorkor was made subsequently upon discovering multiple nutritional deficiencies and clinical nutritional assessment. Kwashiorkor is often underdiagnosed or misdiagnosed in developed countries. The results, if unrecognized, may be devastating. This makes it imperative that physicians consider this diagnosis, recognize potential risk factors, and be prepared to accurately assess overall nutritional status of patients, especially vulnerable populations such as those with trisomy 21 . Additionally, protein malnutrition should be considered in any child presenting with PE unresponsive to conventional treatment.

\section{References}

1. Krebs NF, Primak LE, Hambridge KM (2005) Normal childhood nutrition \& its disorders. In: Hay. Current Pediatric Diagnosis \& Treatment, 17th edn. McGraw-Hill, USA

2. Williams CD (1935) Kwashiorkor: a nutritional disease of children associated with a maize diet. 229: 1151-1152.

3. Carvalho NF, Kenney RD, Carrington PH, Hall DE (2001) Severe nutritional deficiencies in toddlers resulting from health food milk alternatives. Pediatrics 107: 46 .

4. Zemel BS, Pipan M (2015) Growth charts for children with Down syndrome in the United States. Pediatrics 136: 5. 